\title{
A organização da estrutura linguística na visão dos modelos multirrepresentacionais
}

\author{
The organization of linguistic structure in view \\ multi-representational models
}

\section{La organización de la estructura lingúistica en la visión de modelos de multiples representaciones}

Este artigo tem como objetivo avançar na compreensão dos processos envolvidos na organização fonológica e lexical levando-se em conta os pressupostos teóricos levantados na Linguística Probabilística e Fonologia de Uso, conhecidos como modelos multirrepresentacionais. Foi realizada uma revisão bibliográfica com a seleção de uma série de pesquisas que levantam a hipótese que a representação mental é detalhada e apresenta vários níveis de representação, como o nível fonético paramétrico que relaciona-se diretamente às formas fonéticas dos itens lexicais que o falante é capaz de ouvir e produzir, além de outros níveis, como o de decodificação fonética, o lexical, e o nível da gramática fonológica. Todos estes níveis emergindo de generalizações das formas representadas no léxico.
This article aims to advance the understanding of the processes involved in phonological and lexical organization taking into account the theoretical assumptions raised in Probabilistic Linguistics and Usage-based Phonology, known as multi-representational models. A literature review with the selection of a series of studies that raise the possibility that mental representation is detailed was conducted and presents different levels of representation, as the phonetic level Parametric which relates directly to the phonetic forms of lexical items that the speaker is able to hear and produce, as well as other levels, such as phonetic decoding, the lexical and the level of phonological grammar. All these levels emerging from generalizations of the forms represented in the lexicon.
En este artículo se pretende avanzar en la comprensión de los procesos implicados en la organización fonológica y léxica teniendo en cuenta los supuestos teóricos planteados en Lingüística Probabilística y Fonología de Uso, conocidos como modelos de multiples representaciones. Una revisión de la literatura con la selección de una serie de estudios que elevan la posibilidad de que la representación mental se detalla se llevó a cabo y presenta diferentes niveles de representación, como el paramétrico nivel fonético, que se relaciona directamente con las formas fonéticas de las unidades léxicas que el hablante está capaz de escuchar y producir, así como a otros niveles, como la decodificación fonética, el léxico y el nivel de la gramática fonológico. Todos estos niveles emergentes de las generalizaciones de las formas representadas en el léxico.
Palavras-chave: Dinguística, Modelos Multirrepresentacionais, Fonologia de Uso, Fonologia Probabilística.

\section{Autora:}

\section{Sheila Lúcia de Oliveira Bezerra}

Mestre e Doutora em Linguística pela UFRJ; Especialista em Distúrbios da Comunicação Humana pela UNIFESP/EPM; Pós-graduada em Perícia Criminal pela UNB; Fonoaudióloga pelo IBMR e Bacharel em Letras pela UNESA. Professora Titular da Universidade Estácio de Sá.

Email: bezerra15@yahoo.com.br

\section{Introdução}

As pesquisas realizadas nas últimas décadas na área de percepção de fala demonstram o grande interesse dos estudiosos sobre esta questão ainda bastante controvertida. Como o sinal de fala é transformado pelo sistema auditivo que decodifica informações acústicas sobre frequência, intensidade e duração, e como estas informações em conjunto são armazenadas e analisadas tão rapidamente, são questões deste campo. Assim como a palavra falada é reconhecida, como os aspectos fonéticos e fonológicos se estruturam na mente, o que interfere, colabora para este reconhecimento e define a percepção.
Este trabalho parte da hipótese da organização do léxico em redes, que postula que os itens linguísticos não são listados de forma inestruturada, pelo contrário, nele os itens lexicais são armazenados de forma eficiente em uma rede de relações semânticas e fonológicas, ou seja, as regularidades e similaridades observadas nos itens linguísticos são usadas na estrutura de armazenagem. Estas regularidades e similaridades são percebidas pelo falante de forma gradiente e a representação mental destes itens emerge do uso da língua. A representação mental é detalhada e apresenta vários níveis de representação, como o nível fonético paramétrico que relaciona-se diretamente às formas fonéticas dos itens lexicais que o falante é capaz de ouvir e produzir. E outros níveis, como o nível de decodificação fonética, o nível lexical, o nível da gramática fonológica e o nível das correspondências morfofonológicas. Todos estes níveis emergindo de generalizações das formas representadas no léxico. Esta é uma visão dos modelos multirrepresentacionais que difere da visão tradicional onde para cada item lexical há uma única e categórica representação fonológica (Pierrehumbert, 2003; Bybee, 2001).

O objetivo deste trabalho é avançar na compreensão dos processos envolvidos na organização fonológica e lexical levando-se em conta os pressupostos teóricos levantados na 
Linguística Probabilística e Fonologia de Uso. Para tanto foi realizada uma revisão bibliográfica com a seleção de uma série de pesquisas que tratam do assunto de organização fonológica e lexical a partir dos modelos multirrepresentacionais.

\section{Modelos Multirrepresentacionais}

Neste trabalho considera-se a visão dos modelos multirrepresentacionais, que assim são denominados pela hipótese que defendem sobre a arquitetura linguística na mente do falante, onde ocorre a organização do léxico em redes. Nessas redes os itens lexicais são armazenados de forma eficiente através de relações semânticas e fonológicas, onde regularidades e similaridades observadas nos itens linguísticos são utilizados na estrutura de armazenagem. Estas regularidades e similaridades são percebidas pelo falante de forma gradiente e a representação mental destes itens emerge do uso da língua. A representação mental é detalhada e apresenta vários níveis de representação, como o nível fonético paramétrico que relacionase diretamente às formas fonéticas dos itens lexicais que o falante é capaz de ouvir e produzir. E outros níveis, como o nível de decodificação fonética, o nível lexical, o nível da gramática fonológica e o nível das correspondências morfofonológicas. Todos estes níveis emergindo de generalizações do nível fonético (Pierrehumbert, 2003; Bybee, 2001).

\section{Pressupostos Teóricos da Linguística Probabilística e Fonologia de Uso}

A Fonologia de Uso (Bybee, 2001) e a Fonologia Probabilística (Pierrumbert, 2003) compartilham o postulado da existência de um léxico mental, em que itens lexicais estão organizados em redes associativas em função de similaridades fonéticas e semânticas. Além disso, postula-se que estão estocadas as ocorrências de uso dos itens lexicais. Esse postulado implica que são representadas não só as informações distintivas, mas também as redundantes. Ohala e Ohala (1995) e Langacker (1987) observaram que se as propriedades previsíveis são retiradas dos objetos (ou unidades linguísticas), estes se tornam irreconhecíveis. Para Ohala e Ohala (1995) a redundância na representação é essencial para a categorização, argumentando que as pistas perceptuais para a identificação de consoantes, por exemplo, estão em propriedades previsíveis das transições entre articulações no continuum. A teoria que sustenta essa hipótese é a Teoria de Exemplares.

De acordo com a teoria de exemplares, cada categoria é representada na memória por uma nuvem de ocorrências memorizadas da categoria. Essas memorizações são organizadas num mapa cognitivo. Assim, memórias de instâncias semelhantes estão próximas e memórias de instâncias diferentes estão distantes (cf. Pierrehumbert 2001:139). As ocorrências memorizadas exibem um espectro de variações que se mostram nas manifestações físicas da categoria. As mesmas ocorrências memorizadas podem ser submetidas simultaneamente a mais de um esquema de categorização. Se cada ocorrência da categoria é memorizada, então, categorias mais frequentes vão ser representadas por mais ocorrências e as infrequentes por menos. Como consequência, um exemplar - que é uma memória perceptual detalhada - não corresponde a uma única experiência perceptiva, mas antes equivalente a uma classe de experiências perceptivas.

Esta proposta coloca a questão de que mais espaço de memória vai ser utilizado para dar conta da representação. Para sanar o problema de espaço na memória - desde que todas as ocorrências são memorizadas - a teoria de exemplares postula que ocorrências foneticamente semelhantes, mas minimamente distintas não identificadas na percepção, são categorizadas como sendo a mesma ocorrência. Além disso, experiências memorizadas e não atualizadas ou reforçadas podem ser substituídas por outras.

Assim novas ocorrências serão classificadas de acordo com os exemplares já estocados. A codificação perceptiva das novas ocorrências irá localizá-los no espaço paramétrico relevante. Ou seja, o espaço fonético paramétrico representa o mapa quantitativo acústico e articulatório que, na percepção da fala, descreve o código perceptivo do sinal de fala em cada ocorrência, e, durante a produção da fala, descreve o gesto articulatório, como eles se desdobram no tempo e no espaço. A similaridade com outro exemplar memorizado será computada assim como sua distância do exemplar no espaço paramétrico. Para classificar a nova ocorrência, o rótulo mais provável entre os rótulos da vizinhança será computado. Um tamanho fixado de vizinhança em torno da nova ocorrência irá determinar o conjunto de exemplares que influencia a classificação (Pierrehumbert, 2001, 2003).

De acordo com a autora, o espaço fonético paramétrico é apenas o primeiro de cinco níveis de representação do sinal de fala. Outros níveis de representação emergem das generalizações do nível fonético e das representações das palavras no léxico. Como o nível de decodificação fonética, onde o sistema de códigos fonéticos de uma língua abstrai do espaço fonético paramétrico definindo o inventário possível na língua para decodificação das formas das palavras (representação fonológica das palavras). $\mathrm{Na}$ fonologia tradicional, esta categoria é o fonema, considerado a unidade mínima de contraste reconhecida como invariável e independente da posição que se encontra na sílaba. Nesta teoria, no entanto, as representações nesta categoria não são mínimas porque incluem informações redundantes, variação pela posição alofônica, aspectos de prosódia e entonação relativos ao sinal de fala.

Outro nível é o lexical. Cada palavra no léxico do falante tem uma representação de sua estrutura sonora que permite que a palavra seja reconhecida apesar da variação da forma fonética de falantes e de contextos diferentes. Outro nível é o nível da gramática fonológica que abrange a estrutura prosódica e a fonotática. A fonologia representa generalizações sobre forma de palavras no léxico, que são generalizações da fala. A fonologia não é abstração da fala diretamente, mas indiretamente via abstração da forma da palavra. Este nível tem importantes consequências. Primeiro, existem discrepâncias entre um padrão mais forte no léxico e um padrão mais forte na fala encadeada. A discrepância ocorre porque um padrão que é comum na fala encadeada pode ser raro no léxico se este padrão ocorre na fala encadeada resultando de diferentes palavras. Segundo, o tamanho do léxico é pequeno em comparação ao número total de ocorrência de palavras encontradas por uma pessoa. O ouvinte da língua tem a sua disposição uma vasta gama de dados para generalizar sobre a fala que ouviu, como detalhes de pronúncia, por exemplo. O outro nível é o das correspondências morfofonológicas que envolve distribuição de probabilidade sobre um universo de pareamento e coleções de formas de palavras (Pierrehumbert, 2003). Esses níveis se encontram hierarquizados, mas não serialmente, isto é, por hipótese, é a aquisição gradual de itens lexicais e dos gestos articulatórios necessários para a produção que vai estabelecendo as representações nos diversos níveis. 
A hipótese de que o léxico se estrutura em termos de rede de relações entre os itens lexicais é uma proposição dos Modelos Baseados no Uso e conexionistas (cf. Pierrehumbert, 2001; Norris, 1994; Jusczyk e Luce, 2002; Bybee, 2001).

Nos modelos conexionistas as entradas no léxico estão organizadas numa cadeia. Palavras com propriedades similares estão ligadas umas às outras, tanto direta como indiretamente. Tipos de ligação incluem ligações fonológicas (duas palavras compartilham um elemento fonológico e, portanto, ambas estão ligadas a um nó que representa aquele elemento), ligações morfológicas (formas morfologicamente complexas estão ligadas a sua base), e ligações sintáticas e semânticas. $\mathrm{O}$ espraiamento da ativação e a mútua inibição entre formas lexicais explicam o curso de tempo e os resultados encontrados nos estudos tanto de produção quanto de percepção da fala. Em particular, a percepção da fala ocorre conforme a corrente da fala acontece; a ativação se espalha dos elementos fonológicos que são perceptíveis na sinalização para todas as palavras que exibem aqueles elementos naquela ordem; as palavras competem para serem reconhecidas, e um candidato bem sucedido inibe seus competidores fonologicamente semelhantes. A frequência realiza um papel fundamental em tais cadeias, porque os nós ou ligações que são usados frequentemente adquirem altos níveis de ativação. Diferentes níveis de ativação explicam a bateria de resultados experimentais que dizem respeito à velocidade, exatidão, importância e tendências no processo discursivo (cf. Pierrehumbert, 2001).

Bybee (1995) explica seu modelo em redes (network model) assumindo que as propriedades morfológicas das palavras, paradigmas e padrões morfológicos, antes descritos como primitivos, emergem das associações estabelecidas entre as palavras relacionadas na representação lexical. A autora diz que os modelos conexionistas e o modelo em redes são similares em não postular um ponto distinto entre morfologia regular e irregular, como faz o modelo de processamento binário. Os modelos conexionistas e de redes atribuem diferenças entre morfologia regular e irregular por diferenças quantitativas, em particular pela relativamente grande freqüência de estrutura (type frequency) dos padrões regulares. No modelo tradicional, as formas irregulares são listadas no léxico, mas as regulares não, nesse caso, as regulares são obtidas a partir de regras simbólicas. A distinção entre regular e irregular corresponde a uma distinção estrutural importante que faz parte da arquitetura inata da aquisição da linguagem, pois este modelo tem um componente de regras ou módulos que é separado do léxico. No modelo de redes e nos modelos conexionistas formas regulares e padrões irregulares são tratados da mesma maneira e não há separação dos componentes por regras simbólicas.

Nos modelos multi-representacionais, frequência de ocorrência (token frequency) e frequência da estrutura (type frequency) têm papéis importantes e são maneiras distintas de contar a frequência de ocorrência aplicável à linguagem.

Segundo Bybee (2001, p. 10 e 11) frequência de ocorrência é a frequência de ocorrência de uma unidade no uso, usualmente uma palavra em texto corrido - quão frequentemente uma palavra particular aparece. Assim broke (passado de break) ocorre 66 vezes por milhão de palavras no Francis e Kucera $(1982)^{1}$, enquanto a forma de passado damaged ocorre 5 vezes no mesmo corpus. Em outras palavras, a freqüência de ocorrência de broke é mais alta que a de damaged. requênciade estrutura

\footnotetext{
1 Corpus de língua falada do inglês americano disponível para análise computacional.
}

refere-se à frequência de um padrão estrutural particular (um padrão de acentuação, um afixo, ou um grupo consonantal, por exemplo). No inglês, o tempo passado é expresso de diversos modos, mas a expressão com mais alta frequência de type é o sufixo-ed, como em damaged, que ocorre em milhares de verbos. O padrão encontrado em broke tem uma freqüência de type mais baixa, ocorrendo somente em um pequeno conjunto de verbos (spoke, wrote, rode, etc). No espanhol, a penúltima sílaba tônica tem mais alta frequência de type, ocorrendo aproximadamente em 95\% de nomes e adjetivos que terminam em vogal (abuéla, camíno, pronómbre), enquanto a antepenúltima sílaba tônica tem uma mais baixa freqüência de type (cláusula, fonológica). No português temos o morfema -s de plural, os verbos da $1^{\text {a }}$ conjugação terminados em "-ar", como cantar, amar, soltar, vibrar, etc, como exemplo de tipos estruturais frequentes. Já o plural metafônico de novo/novos (vogal aberta do radical na forma de plural) e o paradigma flexional do verbo "ser" são exemplos de tipo estrutural de baixa frequência.

A relação entre frequência de type e token exerce influência na mudança linguística, aquisição e processamento. Por exemplo, um type pouco freqüente pode resistir à mudança analógica se tiver uma alta freqüência de ocorrência. Até o exemplo da forma irregular do passado kept que tende a não sofrer regularização (keep-ed) por ser uma palavra muito usada, ao passo que wept, crept e leapt tendem a regularizar para weeped, creeped e leapede, respectivamente, devido à sua baixa freqüência de ocorrência (Bybee, pág 11-12).

$\mathrm{O}$ termo produtividade se refere à probabilidade de determinado padrão se aplicar a novos itens. Pode também ser contada a frequência de token de tais padrões - quão freqüente o padrão ocorre no uso.

Para a autora, tanto os modelos conexionistas, como seu modelo em redes, defendem que a frequência da estrutura (type frequency) é o maior determinante para a produtividade. No entanto, Bybee (cf. 2001) diz que há algumas diferenças entre o modelo proposto por ela e os modelos conexionistas. Um exemplo é o tratamento da frequência de ocorrência. Em modelos conexionistas a frequência de ocorrência mostra-se como a freqüência do mapeamento entre base e forma derivada. No modelo de redes, é a freqüência da palavra derivada em si mesma que é significante e é representada como força lexical, não um mapeamento entre duas formas. O aumento da freqüência de uma forma derivada enfraquece o mapeamento entre esta e a forma básica. Os itens irregulares com alta frequência são resistentes à regularização não porque suas conexões com suas bases são melhor estabelecidas, mas porque eles são em si mesmos lexicalmente fortes.

Bybee (2001) também afirma que o uso e a experiência estruturam a linguagem e esta estrutura não seria imutável. A autora ainda propôs em seu trabalho demonstrar que o foco na estrutura precisa ser acrescido de uma perspectiva que inclui mais que apenas uma estrutura; uma visão que inclui outros importantes aspectos do fenômeno da linguagem: o conteúdo ou substância e o uso da linguagem. A substância da linguagem se refere a dois pólos: fonético e semântico, que modelam e estruturam a linguagem. O uso da linguagem não inclui apenas o processamento da língua, mas todo o uso social e interacional para o qual a linguagem ocorre. Alguns princípios básicos do Modelo Baseado no Uso da Linguagem incluem:

A experiência afeta a representação - A representação mental sofre influência dos padrões e formas usadas no cotidiano. Certas palavras, por terem uma alta frequência no uso tornam 
sua representação mais forte fazendo com que elas sejam mais facilmente acessadas e provavelmente sofram menos mudança. Enquanto que as palavras de baixa freqüência são mais difíceis de serem acessadas e podem por isso enfraquecer e serem esquecidas. Ou seja, os padrões que ocorrem em mais itens são mais fortes e mais acessíveis, e assim mais produtivos que aqueles que ocorrem em menos itens. Os contextos diversos em que as palavras são usadas podem modificar sua força lexical. Este pensamento é um contraste em relação à abordagem modular em que representações e regras ou restrições são todos estáticos e fixos.

As representações mentais dos objetos linguísticos têm as mesmas propriedades de representações mentais de outros objetos - Considerando que, quando as propriedades previsíveis são retiradas dos objetos, eles se tornam irreconhecíveis, supõe-se que em relação ao domínio dos objetos linguísticos o cérebro operaria do mesmo modo. O resultado desta suposição é que representações mentais não têm propriedades previsíveis abstraídos fora delas, mas antes são firmemente baseados na categorização de ocorrências reais.

A categorização é baseada na identidade ou na similaridade - A armazenagem da percepção fonológica é organizada por um tipo de categorização que pode ser abordada através de experimentação fonética e psicológica assim como através de analogias com outros domínios da percepção. Analisando estruturas linguísticas já podemos identificar diferentes tipos de relação entre objetos linguísticos, como a relação entre dois sinais fonéticos da mesma palavra; em diferentes palavras podemos encontrar padrões do mesmo morfema, e a relação entre dois fones similares em diferentes palavras.

As generalizações sobre formas não são separadas da representação dessas formas, mas emergem diretamente delas - São as relações de similaridade fonética e semântica que ocorrem entre as formas armazenadas que vão tornar possíveis as generalizações sobre formas. Novas formas podem ser produzidas pela referência de formas existentes, mas a maior parte das palavras multimorfêmicas é armazenada como um todo no léxico. A organização lexical permite generalizações e segmentações em vários graus de abstração e generalidades - Os morfemas, os segmentos ou as sílabas são unidades emergentes que procedem da relação de identidade e similaridade que organiza a representação. Há um alto grau de redundância no processo de armazenagem.

Vihman e Croft (2007) apresentam uma outra proposta de organização fonológica, mas que também enfatiza a organização do léxico, o item lexical como central na representação e a emergência da estrutura através de diferentes níveis de abstração que se depreendem das relações entre os itens lexicais. Eles argumentam que a palavra é a unidade básica da representação fonológica. Outras unidades menores que a palavra são definidas em relação ao papel que cumprem na palavra. As categorias de tipos de segmentos e tipos de sílabas são definidas em termos de sua padronização fonotática dentro da palavra. Nesta proposta, a organização fonológica é baseada na classificação hierárquica "botton-up", ou redes de palavras. Segundo os autores, a estrutura desta rede refletirá generalizações fonológicas válidas para a língua. Uma dessas generalizações seriam as categorias fonológicas definidas fonotaticamente em uma língua específica que pode ser mapeado em um espaço fonético. Os mapas fonológicos representam a realização fonética de classes ou categorias de segmentos ou traços em posição fonotática particular. Ou seja, neste modelo, os traços fonológicos também são mapeados no espaço fonético. Um mapa para um traço fonológico pode cobrir uma espaçosa região do espaço fonético. Em sua proposta, a hierarquia, ou rede de representação fonológica desenvolve do modo "bottonup", sendo desta maneira que a criança aprende no ambiente da língua. Segundo eles, a criança começa com a representação de uma forma de palavra individual e gradualmente desenvolve uma série de esquemas fonológicos de modelos de palavras. Este desenvolvimento seria manifesto na seleção e na adaptação de palavras dos adultos para os modelos usados pela criança num particular estágio do desenvolvimento. Lentamente, a criança adquire mais modelos de esquemas e uma gama mais larga de modelos até chegar a um sistema adulto completo (pg. 9-10, 35-36). Esta mesma ideia é observada em Vihman e Kunari (2006) acrescentando, através dos dados encontrados no trabalho realizado com crianças muito pequenas, que a produção articulatória afeta a percepção. A emergência das primeiras palavras estaria relacionada com a estrita ligação entre percepção e produção.

Observa-se, então que todas estas pesquisas corroboram para as mesmas hipóteses de que o léxico é organizado em redes de relações semânticas e fonológicas, a experiência afeta a percepção e as representações são múltiplas. Toda esta abordagem modelos multirrepresentacionais tem avançado rumo à desconstrução de alguns conceitos da tradicional distinção entre competência e desempenho, que nem sempre esteve interessada nos resultados experimentais. Em sua proposta essencialmente teórica, há uma separação estrita entre fonética e fonologia, o léxico está separado da gramática fonológica, e não se considera que os efeitos de frequência de uso são armazenados na memória de longo termo (CHOMSKY \& HALLE, 1968).

\section{Considerações Finais}

$\mathrm{O}$ fenômeno da linguagem humana e os processos que envolvem o reconhecimento da fala merecem ainda muito estudo e investigação para que algumas conclusões possam ser feitas. Porém com base na revisão bibliográfica apresentada neste trabalho, observa-se, que os modelos multirrepresentacionais levantam hipóteses e apresentam tendências que corroboram com a idéia de que o léxico é organizado em redes de relações semânticas e fonológica, ou seja, a armazenagem da percepção fonológica é organizada por um tipo de categorização que pode ser abordada através de experimentação fonética e psicológica assim como através de analogias com outros domínios da percepção; a experiência afeta a percepção, ou seja, a representação mental sofre influência dos padrões e formas usadas no cotidiano.

Para os modelos multirrepresentacionais, a representação mental é detalhada e apresenta vários níveis de representação, como o nível fonético paramétrico que relaciona-se diretamente às formas fonéticas dos itens lexicais que o falante é capaz de ouvir e produzir. E outros níveis, como o nível de decodificação fonética, o nível lexical, o nível da gramática fonológica e o nível das correspondências morfofonológicas. Todos estes níveis emergindo de generalizações do nível fonético.

\section{REFERÊNCIAS}

BYBEE, Joan. Phonology and Language Use. Cambridge University Press, 2001.

BYBEE, J. Regular morphology and the lexicon. Language and Cognitive Processes 10: 425-55, 1995.

CHOMSKY, Noam \& HALLE, Morris. The Sound Pattern of English. 
New York: Harper e Row, 1968.

CROFT, William \& Vihman, Marylin. Radical Templatic Phonology and phonological development, 2005. http://lings.ln.man.ac.uk/Info/ staff/WAC/Papers/RTP.pdf

FRANCIS, W.N. \& H. KUCERA. (1982). Frequency Analysis of English Usage: Lexicon and Gramar. Boston: Houghton Mifflin.

LANGACKER, R. Foundation for a cognitive vol 1, Stanford: Stanford Academic Press, 1987.

OHALA. J \& OHALA, M. Speech perception and lexical representation: the role of vowel nasalization in Hindi and English. Phonology and phonetic evidece. Papers in Laboratory Phonology IV, ed. Bruce Connel and Amalia Arvanti, Cambridge: Cambridge University Press, 1995, p. 41-60

PIERREHUMBERT, Janet B. Probabilistic Phonology: Discrimination and Robustness. Northwestern University. Evanston, IL. January 20, 2003.

PIERREHUMBERT, Janet B. Stochastic phonology. Glot International Vol.5, No.6, June: 195-207; 2001

PISONI, Davi B; NUSBAUM, Howard C; LUCE, Paul A \& SLOWIACZEK, Louisa M. Speech perception, word recognition and the struture of the lexicon. Elsevier Science Publishers B. V. North-Holland. Speech Communication 4 : 75-95; 1985. 